\title{
Best practices for the use and exchange of invertebrate biological control genetic resources relevant for food and agriculture
}

\author{
P. G. Mason · M. J. W. Cock • B. I. P. Barratt • J. N. Klapwijk • \\ J. C. van Lenteren · J. Brodeur · K. A. Hoelmer • G. E. Heimpel
}

Received: 20 February 2017/Accepted: 3 April 2017/Published online: 19 April 2017

(C) The Author(s) 2017. This article is an open access publication

\begin{abstract}
The Nagoya Protocol is a supplementary agreement to the Convention on Biological Diversity that provides a framework for the effective implementation of the fair and equitable sharing of benefits arising out of the utilization of genetic resources, including invertebrate biological control agents. The Protocol came into force on 12 October 2014, and requires signatories and countries acceding to the Protocol to develop a legal framework to ensure access to genetic resources, benefit-sharing and compliance. The biological control community of practice needs to comply with access and benefit sharing regulations arising under the Protocol. The IOBC Global
\end{abstract}

Handling Editor: Russell Messing.

This contribution is an output of the International Organization for Biological Control (IOBC) Global Commission on Access and Benefit Sharing.

Electronic supplementary material The online version of this article (doi:10.1007/s10526-017-9810-3) contains supplementary material, which is available to authorized users.

P. G. Mason ( ()

Ottawa Research and Development Centre, Agriculture and Agri-Food Canada, 960 Carling Avenue, Ottawa, ON K1A 0C6, Canada

e-mail: peter.mason@agr.gc.ca

M. J. W. Cock

CABI, Bakeham Lane, Egham, Surrey TW209TY, UK

e-mail: m.cock@cabi.org
Commission on Biological Control and Access and Benefit Sharing has prepared this best practices guide for the use and exchange of invertebrate biological control genetic resources for the biological control community of practice to demonstrate due diligence in responding to access and benefit sharing requirements, and to reassure the international community that biological control is a very successful and environmentally safe pest management method based on the use of biological diversity. We propose that components of best practice include: collaborations to facilitate information exchange about what invertebrate biological control agents are available and where they may be obtained; knowledge sharing through freely available databases that document successes (and failures); cooperative research to develop capacity in source countries; and transfer of production technology to provide opportunities for small-scale economic activity. We also provide a model concept agreement that can be used for scientific research and non-commercial release into nature where access and benefit sharing regulations exist, and a model policy

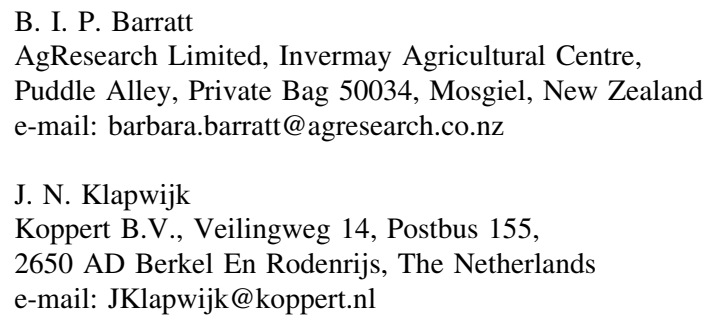

B. I. P. Barratt

AgResearch Limited, Invermay Agricultural Centre, Puddle Alley, Private Bag 50034, Mosgiel, New Zealand e-mail: barbara.barratt@agresearch.co.nz

J. N. Klapwijk

Koppert B.V., Veilingweg 14, Postbus 155,

2650 AD Berkel En Rodenrijs, The Netherlands

e-mail: JKlapwijk@koppert.nl 
for provision of invertebrate biological control agents to other parties where access and benefit sharing regulations are not restrictive or do not exist.

Keywords Biological control - Access and benefit sharing · Best practices - Genetic resources . Invertebrate biological control agent

\section{Introduction}

The Convention on Biological Diversity recognises that countries have sovereign rights over the genetic resources within their boundaries, and thus parties to the Convention have the authority to determine access to these genetic resources (CBD 1993). Agreements governing the access to these resources and the sharing of the benefits arising from their use should be established between the parties involved, including all invertebrate biological control agents (IBCAs) taken from one country (source) to another (recipient) (Cock et al. 2010). The Nagoya Protocol is a supplementary agreement to the Convention on Biological Diversity that provides a framework for the effective implementation of the fair and equitable sharing of benefits arising out of the utilization of genetic resources (Secretariat of the Convention on Biological Diversity 2011) and came into force on 12 October 2014. Signatories and countries acceding to the Nagoya Protocol are required to develop a legal framework to ensure access to genetic resources,

J. C. van Lenteren

Laboratory of Entomology, Wageningen University, P.O.

Box 8031, 6700 EH Wageningen, The Netherlands

e-mail: joop.vanlenteren@wur.nl

\section{J. Brodeur}

Institut de Recherche en Biologie Végétale, Université de Montréal, 4101, rue Sherbrooke Est, Montreal,

QC H1X 2B2, Canada

e-mail: jacques.brodeur@umontreal.ca

\section{K. A. Hoelmer}

USDA - ARS Beneficial Insects Introduction Laboratory, 501 South Chapel Street, Newark, DE 19713-3814, USA e-mail:kim.hoelmer@ars.usda.gov

\section{G. E. Heimpel}

Department of Entomology, University of Minnesota, 508 Hodson Hall, St. Paul, MN 55108, USA

e-mail: heimp001@umn.edu benefit-sharing and compliance. The biological control community of practice needs to comply with access and benefit sharing (ABS) regulations arising under the Nagoya Protocol.

There are two main biological control (BC) approaches that involve the release of living organisms into the environment (Cock et al. 2010). The first approach is the introduction of an IBCA, usually from a pest's area of origin, to control the pest in an area where it has invaded (classical or importation biological control). Once introduced, the IBCA will become established, reproduce and spread, and have a selfsustaining effect on the target pest. This work is typically done by university and/or government researchers and once established, the IBCA becomes a 'common good' available to all. The second category is the commercial production and release of IBCAs by stakeholders such as farmers into specific situations, where they cause population reduction of the target pest, but are not expected to persist from one season to the next (augmentative biological control). Biological control companies identify possible IBCAs for a particular pest-management use, carry out research to develop rearing methods, methods of use, and establish their efficacy. The IBCAs may be indigenous to the country where they are used or they may be exotic species, in which case the principles of access and benefit sharing will apply. Only a proportion of those potential IBCAs originally selected reach a commercial stage. Their sale should eventually generate modest profits, but the benefits to the country where they are used are mostly in terms of reduced pesticide use to the benefit of farmers and consumers. The scope for sharing benefits with the source country is mostly capacity building and shared research.

Allowing access to IBCAs for use in another country imposes no risk of liability to the source country. Furthermore, traditional knowledge has not hitherto been relevant to finding and identifying potentially useful natural enemies. The search for IBCAs should therefore not be confused with bioprospecting (or biopiracy). Equally, IBCAs are not modified genetically. Therefore they cannot be patented, although mass rearing techniques can be trade secrets. Biological control is one of many research-based activities that require access to genetic resources, offer scope for capacity building and shared research, but that is not expected to generate monetary returns that are practical to share. 
IBCAs have played an important role in controlling pests of consequence in agriculture, forestry, human health and the environment (van Driesche et al. 2010; Cock et al. 2015; Heimpel and Mills 2017). In particular, introduction of IBCAs to combat invasive alien species has been and continues to be a primary focus. For example, since its first use in California in 1888, the beetle, Rodolia cardinalis (Mulsant) (Coleoptera: Coccinellidae), has been used to control the cottony cushion scale, Icerya purchasi Maskell (Hemiptera: Margodidae), in more than 50 countries throughout the tropics and subtropics (Cock et al. 2010). Similarly, the highly effective salvinia beetle, Cyrtobagous salviniae Calder \& Sands (Coleoptera: Curculionidae), has been introduced into Australia, India, Kenya, Malaysia, Namibia, Papua New Guinea, South Africa, Sri Lanka, and Zambia, providing spectacular control of giant salvinia, Salvinia molesta D. Mitchell (Salviniaceae) (Winston et al. 2014). In 2009, the Global Commission on Biological Control and Access and Benefit-Sharing of the International Organisation for Biological Control of Noxious Animals and Plants (IOBC) prepared a Background Study Paper on the use and exchange of biological control agents for food and agriculture at the request of the Food and Agriculture Organization (FAO) Commission on Genetic Resources for Food and Agriculture (Cock et al. 2009).

Recommendation 5 of this report states, "A document describing best practices for ABS in relation to $\mathrm{BC}$ including guidelines for joint research that are equitable, but not restrictive, should be prepared and disseminated. BC organisations would be expected to follow these guidelines."

Since the earliest days of modern biological control in the ninteenth century, there has been a community of practice based on free multilateral exchange of IBCAs (Debach 1964), rather than bilateral exchange or defined benefit sharing agreements. Countries are both providers and users of IBCAs. It has usually made good practical sense to collaborate with a research organisation in a (potential) source country, and the need for collaborative research in the source country has grown together with the need for more detailed risk and environmental impact assessment studies. Conversely, there is a general trend for access to genetic resources, including IBCAs, to become increasingly restrictive, for a variety of reasons, including ABS regulations and, in the case of biological control, phytosanitary legislation. The existing multilateral free exchange ethos and effective global networking of biological control practitioners are foundations that deserve special consideration with regards to $\mathrm{ABS}$.

The IOBC Global Commission on biological control and ABS endorses this approach and recommends the following Code of Best Practices for Biological Control. These guidelines consider IBCAs specifically. A similar approach applies to microbial biological control agents, but with some differences, and the IOBC Global Commission intends to develop separate guidelines for these.

\section{Best practices for exchange of invertebrate biological control genetic resources}

Informal networks

Informal cooperative networks of biological control practitioners around the world, involving scientists working with government agencies, intergovernmental organisations, international agricultural research centres, universities, industries, etc. are best suited to assist biological control practitioners for the free multilateral exchange of invertebrate biological control agents. This practice is especially important in biological control against pests of agricultural crops, where the recipient country might be seen as an economic competitor of the source country which may also be the origin of the pest. While the recipient country clearly benefits, the source country may have earlier benefited by accessing an IBCA supplied by the former country for a different pest, or the source country expects to benefit in turn, when it needs access to an IBCA. Informal networks are particularly effective when it comes to providing known IBCAs, e.g., from a country where they are native or have already been introduced, and in the case of redistribution of a recently introduced IBCA within a country.

Information on invertebrate biological control agents

Knowledge of which IBCAs have been used, where, and how successfully is an important issue for good 
practice. Although this information is often available in the published literature, finding it may be a problem if the literature is extensive. Databases on the biological control of invasive weeds and insect pests using IBCAs are available and it is encouraged that these be maintained up to date and be made publicly available to improve access to known genetic resources for use in biological control. For example, CABI's BIOCAT database provides information on IBCA releases on a global scale (Cock et al. 2016) and the fifth edition of Julien's catalogue of weed biological control agents (Winston et al. 2014) provides a global database on biological control agents of weeds. Regional databases such as for the United States and Territories (USDA 2016) and New Zealand (Ferguson et al. 2007; NZEPA 2016) are also helpful. Information on commercial biological control agents is also available from the International Biocontrol Manufacturers' Association (http://www.ibma-global.org) based in Europe and the Association of Natural Biocontrol Producers (http://www.anbp.org) based in North America.

For IBCAs, once the identity is rigorously established all other sources of information can be used for research and for a better understanding of the organism. The vast amount of data available in the published literature and through internet-based databanks has become accessible, often free of charge in sources such as gene banks (e.g., National Center for Biotechnology Information), literature services (e.g., CAB Direct, Google Scholar, Web of Science, AGRICOLA), collections of journals and their archives (e.g., JSTOR, AJOL, Bioline International), and other compilations of specialised information (e.g., CABI Invasive Species Compendium, CABI Crop Protection Compendium, Encyclopaedia of Life, natural enemy websites such as the Universal Chalcidoidea Database, Taxapad, etc.).

Gaining access to invertebrate biological control agents

Biological control agents are living organisms found in nature, and if they have not been previously used in biological control, they may be of largely unknown relevance and value. They need to be collected from the field, studied, cultured (usually) and transported by hand, air-freight, or post to the receiving country/countries. Access and permission to export currently depend on national regulations, the legislation for which may or may not address ABS issues. Governments are normally focused on protecting and enhancing the value of their biodiversity and legislation is based on that interest, although sometimes their ABS regulations may emphasize the economic aspect which can impede the use of their biodiversity. To safeguard these interests, benefit sharing agreements that encourage the maximum amount of research and development are a good tool to enable IBCA exchange (Biber-Klemm et al. 2010). Supplementary Information S1 gives an example of such a concept agreement that can be used for scientific research and noncommercial release into nature, where ABS regulations are in place.

Where ABS regulations are not restrictive or do not exist (e.g., countries that have not ratified the Nagoya Protocol), establishing a policy for provision of IBCAs to other parties can be an effective way for organizations to easily provide material to a partner. Such a policy protects the supplier by setting out the conditions under which IBCAs can be provided or should not be provided (Supplementary Information S2).

The research process and opportunities for benefit sharing

Preliminary surveys for the target pest and its natural enemies will often need to be carried out in several countries. These surveys offer limited opportunities for financial benefit sharing, but benefit the source country through provision of training in survey methods, joint surveys, capacity building and information generated to better understand biodiversity. A subset of specimens of pests and natural enemies would normally need to be exported for identification and taxonomic studies, but most samples often remain in the source country and can be added to local museum collections. This is often seen as a significant benefit to local scientists and educators.

Detailed studies on invertebrate natural enemies to assess their potential as biological control agents must in part be carried out in the source country, while hostspecificity studies involving plants or animals not naturally occurring in the source country would best be carried out in quarantine in the target country or in a third country. It is this stage of a biological control programme that provides great scope for collaboration, shared research and capacity building through 
collaboration between scientists in the source and target countries. These activities often lead to coauthorship on articles in peer-reviewed scientific journals, which can greatly enhance the careers of scientists in sources countries. Often, scientists from source countries visit target countries and may obtain graduate degrees there as part of these collaborations.

In source countries, local partners are essential to carry out biological control surveys and research, and forming these partnerships complies with the spirit of benefit sharing. Some of these local partners will become the leaders in developing biological control options for their country in the future and thus these collaborations can contribute greatly to capacity building in source countries.

Legal or technological considerations on use and exchange of invertebrate biological control agents

\section{Patenting and production}

Organisms such as those used as IBCAs cannot be patented as they are not modified or improved. Therefore, IBCAs are a public good. To protect intellectual property, augmentative biological control companies may establish patents on rearing processes and novel uses or applications, but more usually that knowledge is proprietary. It may be possible to patent individual strains of IBCAs in the future, such as an acaricide-resistant predatory mite, or a predatory arthropod or entomopathogenic nematode selected for heat tolerance. However, the relatively low income and profits of augmentative biological control firms makes development of these types of strains for patenting less likely, as the high development cost will often not be justified by the expected sales (Cock et al. 2009).

\section{Licensing production}

The larger augmentative biological control companies are already able to license production to smaller companies, and this provides one way to facilitate setting up new companies in new countries to supply new markets. This could include the source country and therefore could generate a novel economic activity there. Commercial augmentative biological control companies can and do buy IBCAs from each other on occasion.

\section{Conclusion}

Implementation of access and benefit sharing regulations will change how biological control is conducted. The use of Best Practices is key to ensuring that the global biological control community has continued access to new and existing agents. The practices proposed here provide the necessary guidance for the global biological control network to maintain a high standard for use and exchange of biological control agents to solve important pest problems and protect biodiversity.

Open Access This article is distributed under the terms of the Creative Commons Attribution 4.0 International License (http:// creativecommons.org/licenses/by/4.0/), which permits unrestricted use, distribution, and reproduction in any medium, provided you give appropriate credit to the original author(s) and the source, provide a link to the Creative Commons license, and indicate if changes were made.

\section{References}

Biber-Klemm S, Martinez SI, Jacob A, Jevtic A (2010) Agreement on access and benefit sharing for non-commercial research. Swiss Academy of Sciences, Bern. https://www.cbd.int/abs/ doc/model-clauses/noncommresearch-abs-agreement.pdf. Accessed 18 Jan 2017

CBD (Convention on Biological Diversity) (1993) Convention on Biological Diversity (with annexes). concluded at Rio de Janeiro on 5 June 1992. United Nations-Treaty Series 1760(30619), pp 142-382

Cock MJW, van Lenteren JC, Brodeur J, Barratt BIP, Bigler F, Bolckmans K, Cônsoli FL, Haas F, Mason PG, Parra JP (2009) Use and exchange of biological control genetic resources relevant for food and agriculture. FAO Genetic Resources Commission by the IOBC Global Commission on Biological Control and Access and Benefit Sharing. FAO Background Paper 47

Cock MJW, van Lenteren JC, Brodeur J, Barratt BIP, Bigler F, Bolckmans K, Cônsoli FL, Haas F, Mason PG, Parra JP (2010) Do new access and benefit sharing procedures under the convention on biodiversity threaten the future of biological control? BioControl 55:199-218

Cock MJW, Day RK, Hinz H, Pollard KM, Thomas SE, Williams FE, Witt ABR, Shaw RH (2015) The impacts of some classical biological control successes. CAB Rev 10:1-57

Cock MJW, Murphy ST, Kairo MTK, Thompson E, Murphy RJ, Francis AW (2016) Trends in the classical biological control of insect pests by insects: an update of the BIOCAT database. BioControl 61:349-363 
DeBach P (1964) Successes, trends, and future possibilities. In: DeBach P, Schlinger EI (eds) Biological control of insect pests and weeds. Chapman and Hall Ltd., London, pp 673-713

Ferguson CM, Moeed A, Barratt BIP, Hill RL, Kean JM (2007) BCANZ-biological control agents introduced to New Zealand. http://www.b3nz.org/bcanz. Accessed 20 March 2017

Heimpel GE, Mills NJ (2017) Biological control: ecology and applications. Cambridge University Press, Cambridge

New Zealand Environmental Protection Authority (2016) Biological control agents approved for use in New Zealand. http://www.epa.govt.nz/new-organisms/popular-no-topics/ Pages/biological-control-agents.aspx. Accessed 3 Feb 2017

Secretariat of the Convention on Biological Diversity (2011) Nagoya protocol on access to genetic resources and the fair and equitable sharing of benefits arising from their utilization to the Convention on Biological Diversity: text and annex. Convention on Biological Diversity, United Nations, Montreal, Canada

USDA (United States Department of Agriculture (2016) Releases of beneficial organisms in the United States and Territories (ROBO) http://www.ars-grin.gov/nigrp/robo. html. Accessed 3 Feb 2017

van Driesche RG, Carruthers RI, Center T, Hoddle MS, HoughGoldstein J, Morin L, Smith L, Wagner DL, Blossey B, Brancatini V, Casagrande R, Causton CE, Coetzee JA, Cuda J, Ding J, Fowler SV, Frank JH, Fuester R, Goolsby J, Grodowitz M, Heard TA, Hill MP, Hoffmann JH, Huber J, Julien M, Kairo MTK, Kenis M, Mason P, Medal J, Messing R, Miller R, Moore A, Neuenschwander P, Newman R, Norambuena H, Palmer WA, Pemberton R, Perez Panduro A, Pratt PD, Rayamajhi M, Salom S, Sands D, Schooler S, Sheppard A, Shaw R, Schwarzländer M, Tipping PW, van Klinken RD (2010) Classical biological control for the protection of natural ecosystems: past achievements and current efforts. Biol Control 54:S2-S33

Winston RL, Schwarzländer, Hinz HL, Day MD, Cock MJW, Julien MH (2014) Biological control of weeds A world catalogue of agents and their target weeds (5th Edition). USDA Forest Service, Forest Health Technology Enterprise Team, Morgantown. FHTET-2014-04

Dr. Peter Mason Chair of the Commission, conducts research on biological control of arthropod pests and contributes to developing biologically based regulatory oversight of biological control.

Dr. Matthew Cock is CABI's chief scientist and an honorary member of the International Organization for Biological Control.

Dr. Barbara Barratt past-president of IOBC Global, works on risk assessment for biological control of insect pests to provide decision support for regulators.

Johannette Klapwijk is Regulatory Affairs Manager Entomology at Koppert B.V. in the Netherlands and member of the Working Group on Access and Benefit Sharing of the International Biocontrol Manufacturers Association (IBMA).

Dr. Joop van Lenteren works on behavioural ecology and population dynamics of parasitoids and predators, theoretical and practical aspects of biological control, IPM and sustainable crop production.

Dr. Jacques Brodeur holds the Canada Research Chair in Biocontrol and studies the biology and ecology of natural enemies used for biological control of arthropod pests.

Dr. Kim Hoelmer conducts research on biological control of invasive arthropod pests for USDA/ARS.

Dr. George Heimpel's research focuses on biological control using parasitoids; he teaches biological control and is currently the president of IOBC Global. 